ISSN 2227-7102

www.mdpi.com/journal/education

Article

\title{
Women and Gender Equality in Higher Education?
}

\section{Miriam E. David ${ }^{1,2}$}

1 Institute of Education, University College London, 20 Bedford Way, London WC1H 0AL, UK; E-Mail:m.david@ioe.ac.uk

2 Centre for Higher Education and Equity Research, University of Sussex, Brighton, BN1 9RH, UK

Academic Editor: John Blewitt

Received: 15 January 2015 / Accepted: 3 February 2015 / Published: 16 February 2015

\begin{abstract}
I look at the changes in higher education (HE) and women's lives over the last 50 years, drawing on my recent book Feminism, Gender \& Universities: Politics, Passion \& Pedagogies which is a life history of feminism entering academe. The Robbins Report (cmnd 2154 1963) on HE was published in the same year that I went to university. It inaugurated a process of change and educational expansion that was linked to other major social transformations, including feminism. Its effects have been widely felt such that women now participate in education and employment on unprecedented levels. Indeed, it has opened up opportunities for education and employment for women including individual and social mobility. From my study I show how it opened up opportunities for women from both middle class and working class backgrounds to be first-in-the-family to go to university. I will also argue that whilst there have been very welcome changes in education, and HE especially, such that there is a gender balance of undergraduate students in HE, this does not mean that gender equality has been achieved. Patriarchy or hegemonic masculinity in HE is still strongly felt and experienced despite women's and feminist involvements in academe over the last 50 years. The question remains about how to transform universities to achieve genuine gender equality across all students and academics in HE.
\end{abstract}

Keywords: equality; feminism; gender; higher education; misogyny; patriarchy 


\section{Introduction}

Over the last 50 years, the pace of change in HE linked to the wider economy has speeded up such that women now comprise over 50 percent of university undergraduate students across most countries, especially the developed world or "global north", although these percentages do not translate into academia and nor do they transform gender relations [1-3] The differences are stark, as I shall show: the gender gap has reversed for undergraduate students but for women as academics it remains resistant to change as male power dominates. The question of gender equality in universities, and the contribution of feminist or women's studies is a highly contentious topic. The claim that gender equality has been achieved only refers to the question of the balance of male and female students, whether of undergraduate or graduate degrees and courses [4]. It is not at all about women as academics, teachers or researchers, and yet feminist knowledge, pedagogies and wisdom have developed apace as feminists have entered global academe. She Figures, a European Union publication [2], illustrates how limited women's penetration into the senior ranks of university research and administration has been, whilst the annual reports of the UK's Equality Challenge Unit (ECU) [1] do not acknowledge the rampant inequalities between students and academics.

Drawing on my recently published Feminism, Gender \& Universities: Politics, Passion \& Pedagogies [5], I present a global picture to contextualise the collective biography and life history of international feminists entering HE over the last 50 years. I argue that the feminist project to transform women's lives in the direction of gender and social equality became not only a political but also an educational and pedagogical one. Feminism has transformed women's lives and the processes of knowledge-making, but it has yet to have a wider impact upon gender and sexual relations, given the parallel changing socio-economic contexts towards managerial and business approaches to university. I interviewed over 100 international academic feminists and activists, across three generations, and whilst their particular biographies and experiences were different, all felt that feminism had transformed their personal and professional lives. HE was critical to this with comments like:

- Feminism has been my life project

- It changed my life

- My entire life has been shaped by feminism

- As a scholar I write from a feminist perspective

- I began to self-identify as a feminist when I was in graduate school...

The first generation (born around the second world war), those who are now known as second-wave feminists, to distinguish them from first-wave feminists who fought for women's suffrage, tended to become feminists through their political and personal circumstances, after being students at university, when "second-wave feminism broke on the shores of academe". The second generation illustrate the ripple effects of feminism moving into academe, mainly becoming feminists through their studies as teachers or researchers, whilst the third generation are illustrative of the "crest of the wave" of academic feminism: when feminist and gender studies become part of the curriculum of undergraduate studies. Whilst all feel passionate about feminist knowledge and feminist pedagogies, none are sanguine about the future, feeling that issues about gender and social equality have been captured by neo-liberal discourses and where they have lost their radical and transformative edge. 


\section{Global Commitments to Gender Equality in HE}

UNESCO's World Atlas of Gender Equality in Education, published in 2012 [3], is the clearest example of this international commitment to global gender equality across and including all levels of education. This atlas provides a vast amount of statistical information about where women and men are as students across the globe, relating the information to international criteria. It is quite clear from the publication of a global atlas that education is a vital ingredient of economies today and that the goal of universal education for all is fast becoming a reality. The title of illustrates quite how normal the issue gender equality has become. So has the goal of gender equality been accomplished, or are there still issues about the relations between men and women in higher or tertiary education and beyond? Or, on the other hand, has the notion of gender equality been captured by the ruling classes or governing elites and been changed to a modest one of access and inclusion, rather than a wider notion of transformation of power relations?

Even the UNESCO Atlas argues that whilst there has been enormous growth in student numbers, including a 500 percent increase across the globe, over the last 40 years, women do not benefit as well as men from their involvement in HE. This is their headline: Women now account for a majority of students in most countries [and this is part of] an increase of around 500 percent in enrolments over less than 40 years (1970-2009). They add that "the capacity of the world's education systems more than doubled — from 647 million students in 1970 to 1397 million in 2009 ... [and] from 33 to 164 million in higher education" [3] (p. 9). They go on that "female enrolment at the tertiary level has grown almost twice as fast as that of men over the last four decades (my emphasis) for reasons that include social mobility, enhanced income potential, international pressure to narrow the gender gap ... [but] access to higher education by women has not always translated into enhanced career opportunities, including the opportunity to use their doctorates in the field of research" [3] (p. 75). So whilst "the female edge is up in tertiary enrolment through the master's level [it] disappears when it comes to PhDs and careers in research" (my emphasis) [3] (p. 107).

They also say that "Even though higher education leads to individual returns in the form of higher income, women often need to have more education than men to get some jobs... Women continue to confront discrimination in jobs, disparities in power, voice and political representation and laws that are prejudicial on the basis of their gender. As a result well-educated women often end up in jobs where they do not use their full potential and skills" [3] (p. 84). Clearly, there is much that remains to be done to transform the relations between men and women both in HE and beyond. Men still wield more powerful positions within and beyond HE.

My question is how much of these changes are to do with feminism or are they to do with feminism or to do with other socio-economic and cultural changes? As feminists we argued for political changes on the basis of our emerging views of the ways that our personal lives were not unique. We argued that the relations between men and women, in the family, and in the wider public and social world, were political, in the sense of being about power, and inequalities of power in the minutiae of everyday relations. The slogan "the personal is political" was coined to express these sentiments almost 50 years ago. It is being re-invoked today and used to think about the nuances of the power relations within the new forms of $\mathrm{HE}$ in a changed and now knowledge economy. The question of the future of feminist 
knowledge and pedagogies as well as gender equality in neo-liberal forms of HE remains contested. How are we to create a feminist friendly future through HE?

\section{Contested Evidence about Gender and Equality in HE}

The Rt. Hon. David Willetts, when Minister for Universities and Science in the UK Coalition government, produced a pamphlet entitled Robbins Revisited: Bigger and Better Higher Education [6] for the fiftieth anniversary of the report. He claimed that "in 2011-2012...54 per cent of full time students at UK HEIs were female" [6] (p. 26), arguing that this comes from "a shift in the gender balance in higher education". He added that "the situation we face in today's society is one that might have seemed unlikely in 1960s Britain, with more women entering university than there are men even submitting a UCAS form. This is a remarkable achievement for women, who were outnumbered in universities by men as recently as the 1990s. It is also the culmination of a longstanding educational trend, with boys and men finding it harder to overcome obstacles in the way of learning. It is a real challenge for different policy-makers (my emphasis) [6] (pp. 27-28)". Willetts laments this shift in the gender balance in HE.

In his book The Pinch [7] he argued for policies to rectify the balance towards men, as he feared that "feminism had trumped egalitarianism" and university-educated women were to blame for taking working class men's jobs. The book was published in April 2011 in paperback with a new justifying afterword which restates the book's purpose: to deal with injustice between generations rather than social or ethnic groups, while gender relations are taken for granted. He wants to ensure that working class men are encouraged into HE, at the expense of middle class women, albeit that the overall numbers of students applying for HE are declining, given the imposition of tuition fees. Heralded as a brilliant scholar or "two-brains" [8] (p. 4) it seems to me that these arguments are not at all brilliant and that he is the reciprocal of this, namely a "half-wit".

Similarly She Figures [2] from the European Union in 2009 show that the proportion of female students (55\%) and graduates (59\%) exceeds that of male students. Another example has been expressed in the USA, by The Chronicle of Higher Education [9], the magazine for academe, in a special issue on "Diversity in Academe: The Gender Issue". As the editor notes: ...It's well known, for example, that female undergraduates outnumber their male counterparts (my emphasis)...the undergraduate gender gap is especially striking among black students...women are advancing in the professoriate as well... [9] (Carolyn Mooney, senior editor, B3).

There are several sources of evidence providing the detail that confirm the overall picture of moves towards gender equality amongst students in the UK. Willetts does not seem at all abashed by providing comments to right "the gender balance". And he is supported in this by several independent organizations, for example, the Higher Education Policy Institute (HEPI), under the directorship of Barham Bekhradnia, produced a study [4] in 2009 entitled Male and female participation and progression in higher education, which purported to show that since women were now in the ascendance as full-time undergraduate students there was no longer any problem with questions of gender equity, let alone equality in HE.

As regards universities, the organization of university leaders or vice-chancellors, now the Universities UK (UUK), set up a unit to gather together gender statistics, initially named as its Equalities Unit, in the early 21 st century. It has been transformed over the last decade in line with neo-liberal 
tendencies. Although continuing to be financed by public funds, across the four nations of the UK, the unit is no longer under the umbrella of the UUK, but has become an independent and autonomous organization, renamed the Equalities Challenge Unit (ECU). In its current guise it provides detailed evidence about Equality in Higher Education in annual reports that gather together statistics across various social groups including gender, ethnicity, disability, and age, and bringing them together in what are referred to as "multiple identities". Its mission statement [1] in 2013 declared: "ECU works to further and support equality and diversity for staff and students in $\mathrm{HE}$ and seeks to ensure that staff and students are not unfairly excluded, marginalised or disadvantaged because of age, disability, gender identity, marital or civil partnership status, pregnancy or maternity status, race, religion or belief, sex, sexual orientation, or through any combination of these characteristics or other unfair treatment." Since that time, its website has been revised and updated and the statement about its mission now reads as follows: "We support universities and colleges to build an inclusive culture that values the benefits of diversity, to remove barriers to progression and success for all staff and students, and to challenge and change unfair practices that disadvantage individuals or groups" [1]. This is elaborated as: "We believe that the benefits of equality and diversity and inclusive practice are key to the wellbeing and success of individuals, the institution's community, the competitiveness and excellence of institutions, and to the growth of the sector in a global economy. Our priorities have been developed in consultation with institutions, sector bodies, partner organisations and individuals, which has allowed us to focus on the needs of the sector" [1]. This now indicates just how limited gender equality is within the priorities of the ECU, despite the fact that they have created a series of equality charter marks, including ones on gender equality. For instance, one of these now includes: "Addressing gender inequalities and imbalance in the arts, humanities and social sciences, in particular the underrepresentation of women in senior roles."

In announcing the ECU's Equality in higher education: statistical report 2011 (December 2011) on the website [1] it was argued that: "This report presents an equality-focused analysis of information on staff and students during the 2009/10 academic year, plus a year-on-year comparison showing the progress of equality across the sector over the last five years. For the first time the report looks at the interplay of multiple identities (for example female black staff, male disabled students). Covering England, Wales, Scotland and Northern Ireland, the report provides a useful benchmark for institutions to compare their local statistics. New legal requirements across England, Scotland and Wales mean that HE institutions need to set equality objectives or outcomes. The figures in this report, alongside information gathered at a local level, will provide an evidence base that will inform these objectives."

This was ECU's most detailed report thus far, and was split into two parts. Part 2 students (2011) does not start with headline figures about gender equality or parity but provides detail on other equalities such as disabilities, with the comment that "the statistic on the cover shows the difference between students declaring a disability in different subjects. $14.4 \%$ of students studying creative arts and design declared a disability, compared with $4.5 \%$ of students on business and administration studies courses ..." [1] (cover). The overwhelming impression was that gender equality has become so normalized that it hardly bears comment. The authors argued that: "in the academic year 2009/10, women made up $56.6 \%$ of the student population. Female students were in the majority across all four countries (England, Wales, Scotland and Northern Ireland)". Of the almost 2.5 million students in the UK, 1.4 million are women, and the rest—just over a million-are male. However, this fact is 
qualified, as was the case with UNESCO atlas [5], although a similar gloss is not put on the figures, with the statement that "Women were in the majority across all degree levels and modes with the exception of full-time postgraduates where $50.4 \%$ were male... The proportion of female students was highest amongst other undergraduates $(64.7 \%)$..."

Willetts [6] also elaborates on these figures with the comment that: "In the 1960s only 25 percent of full-time students at UK institutions were female... The number of women studying has grown by a larger proportion than the number of men across every subject. Women are still under-represented in sciences (maths and physics) and the applied sciences (computing, engineering, technology and architecture), but the margin has narrowed from the 1960s when only three per cent of students studying "applied science" were women. Arguably the most dramatic increase is in medicine: in the 1960s only 22 in every 100 medical students were women, but by 2011-2012 this had risen to 59 in every 100" [6] (p. 27).

\section{Rampant Gender Inequalities in HE: The UK Academic Labour Market}

It is fascinating that the two reports on Equality in $H E$ by the ECU [1] in the UK can be written and published together without any overarching comment about the dissonance between the two in terms of gender equity. This still remains the case, despite the moves to develop charter marks. No comment is still made about the dissonances, except a goal of "reducing lack of women in senior roles". It is abundantly clear that despite the huge increases in educational opportunities up to postgraduate research where women have been sufficiently able to attain as much if not more than men, that they remain subordinate across all sectors of academic employment. The picture painted by the ECU for students is one of gender having become a minor issue in relation to student attainment and progression, across a range of subjects and disciplines. The ECU's report Equality in higher education part 1: staff [1] (December 2011) paints an entirely different picture: it is one of rampant gender inequalities. The headline figures are prefigured on the cover with the caption: $16.3 \%$ median gender pay gap and $20.3 \%$ mean gender pay gap. "The statistic on the front cover shows the median and mean pay gaps between male and female staff working in higher education across the UK (Figure 1.28)" [1]. The headline figures also paint a similar story of gender inequalities with the following highlighted:

- Overall in 2009/10, 53.8\% of all staff were women.

- Female staff made up $46.8 \%$ of full-time staff and $67.1 \%$ of part-time staff.

- A higher proportion of staff in professorial roles were male $(80.9 \%)$ than female $(19.1 \%)$.

- The mean salary of female staff was $£ 31,116$ compared with $£ 39,021$ for male staff, an overall mean pay gap of $20.3 \%$.

- $\mathbf{7 6 . 1 \%}$ of UK national staff in professorial roles and $67.4 \%$ of non-UK national staff in professorial roles were white males. (my emphases)

All the policy discussion is focused upon students, and especially the dilemma of there being more female than male undergraduates. There is no concern at all about the fact that women are still subordinate within the staffing of HE. As we look across the echelons of HE women become more and more rare, most especially for Black and Minority Ethnic groups. The white male remains legitimately in power in $\mathrm{HE}$ and this remains the case because of the limited shifts in the overall political culture despite educational and socio-economic change. Indeed, moves to neo-liberalism have obscured the lack of overall shifts in gender equality in labour markets and political systems. 


\section{HE and Women 50 Years Ago}

It is clearly the case that $\mathrm{HE}$ is far more prominent in public life and employment than 50 years ago globally and nationally. The Robbins report [10] was commissioned in 1961 by a British Conservative government. There was anxiety at the time about how to sustain and develop economic growth in the post-war era, and education was gradually seen as a key strategic component, given other international developments. The government therefore appointed an eminent economist to chair the proceedings, namely Lord Lionel Robbins, who was a professor at the London School of Economics. He was commissioned to report on the state and future of $\mathrm{HE}$ and its contribution to economic growth. The commitment to economic growth was one of a series of measures embarked upon by the then Conservatives, given that Robbins' report [10] was published less than 20 years after the ending of the Second World War.

The policy to expand HE was not initiated through the Robbins report, but rather the Government wanted Lord Robbins and his committee to legitimate and enhance a policy already set in train. By the beginning of the 1960s, the government, through its autonomous University Grants Committee (UGC) had already sanctioned the expansion of HE and the creation of new universities on green field sites. It was a time of commitment to social and economic change, to human and civic rights, in the shadows of the war. Governments were committed to trying to bring about social change and peaceful solutions. There was what has since been described as a bipartisan social consensus [5] on the role of the state in social and economic policies, and especially around the uses of education and the expansion of educational opportunities. But at that time there was no system for education beyond the compulsory stage, which in the UK had only just been raised to the age of 16. Institutions had grown up in response to different and specific economic needs such as teaching and technologies. Hence there were separate and often locally funded and supported colleges of technology and teacher training.

The Robbins report on Higher Education [10] was published in Autumn 1963. Its main recommendations were to create a system whereby HE could expand. To that end, the committee recommended that "university places should be available for all...qualified by ability and attainment". This quickly became known as the Robbins principle. To ensure that the recommendations were enacted the committee also recommended a commitment of public funds to expand and create a system of HE. The report also concluded that such institutions should have four main "objectives essential to any properly balanced system: instruction in skills; the promotion of the general powers of the mind so as to produce not mere specialists but rather cultivated men and women; to maintain research in balance with teaching, since teaching should not be separated from the advancement of learning and the search for truth; and to transmit a common culture and common standards of citizenship."

At the time, HE reached a very small segment of the population, and university education was an even smaller proportion and the official figures and statistics in the UK did not routinely produce them in terms of sex or gender. There were 216,000 undergraduate (and postgraduate) students overall then [10] (p. 15). Given that university was not crucially important for professional employment, such as the law, many men did not go. And some of the women who went on to gain qualifications in what were then seen as key female occupations - teachers, nurses and social workers - did not have to go to university but to specialist schools and colleges. Willetts makes the point that of the 216,000 students in 1962-1963, only 118,000 went to universities, and the other 98,000 went to other institutions, such as 
colleges of technology, teacher training colleges [6] (pp. 22-24). He adds "in the 1960s only 25 percent of full time students at UK institutions were female" [6] (p. 26).

The period was also about the rise of the social sciences within universities, linked as it was to social reforms and social welfare. Indeed, Willetts' [6] newly constructed tables for his commentary on Robbins show these developments and changes quite dramatically. In his table 3.2 entitled Full-time university students by sex and faculty, 1961-1962 and 2011-2012 he shows that in 1961-1962 there were only five groups of faculties or subjects, namely humanities, social studies, science, applied science and medical subjects. The balances for all students were that a third were in humanities, a quarter in science, and almost 20 percent in applied science, with just over one in ten in social studies and almost a sixth in medical subjects. So in 1961-1962 across all faculties there were $75 \%$ men and 25\% women. Women's proportion was the highest in humanities where there were $42 \%$ women and this represented over half of all women students $(53 \%)$.

By 2011-2012, these faculty groupings had increased to include other subjects and, far more importantly for my story the balances between both the faculties and men and women had completely reversed! In 2011-2012 social studies accounted for almost a third of all students, and humanities had dropped to one in ten, whilst science and applied science had also reversed in balance too so that a quarter of all students are now in applied sciences and only 12 percent in science, with now only 4 percent being in medical subjects! It is clear, then, that there has been a major growth in the social sciences and accompanying this phenomenal growth has been the rise of women as students. Women now represent 54 percent of such students and men only 46 percent, with women being the majority (almost two-thirds in humanities and other subjects (65\%), and well over half in medicine (59\%) and social studies (57\%). It seems clear where the rise in interest in social change has been developed, and how feminism might have taken hold.

In considering ways to finance all of this expansion, the Robbins committee also considered the nature of the culture and society of the time. It noted the balance between male and female students and noted how few women students were attending university at the time: there were far more than twice as many men as women as students at the beginning of the 1960s. Only two and a half percent of 17-30 year old women went to university, whereas almost six percent of men went. It also, however, noted that parents were then expected to support their daughters on marriage. The Robbins committee, therefore, argued against the implementation of student loans, especially as to the potential impact that they would have on parental decision-making about their daughters. They were opposed to student loans because: "In particular, where women are concerned, the effect might well be either that British parents would be strengthened in their age-long disinclination to consider their daughters to be as deserving of higher education as their sons, or that the eligibility for marriage of the more educated would be diminished by the addition to their charms of what would be in effect a negative dowry." (my emphasis) [10] (p. 646)

They also added that: "On balance we do not recommend immediate recourse to a system of financing students by loans. At a time when many parents are only just beginning to acquire the habit of contemplating higher education for such of their children, especially girls, as are capable of benefiting by it, we think it probable that it would have undesirable disincentive effects. But if, as time goes on, the habit is more firmly established, the arguments of justice in distribution and of the advantage of increasing individual responsibility may come to weigh more heavily and lead to some experiment in this direction." (my emphasis) [10] (chap. 14) 
The government of the time accepted all the recommendations of the Robbins committee and set about expanding the university system, including encouraging the provision of more places for women, although this might, as Willetts mentions, have proved difficult: "The Robbins report appeared fifty years ago, in October 1963. It was a remarkable year: ... staggered by the assassination of JFK in November. Aldous Huxley died but the title of his most famous book, Brave New World, was an apt description of the age. It was a big political year too. On 1 October 1963, Harold Wilson promised the "white heat" of a new technological revolution at the Labour Party Conference. A few days later, during the Conservative Party Conference, Harold Macmillan resigned as Prime Minister, citing some health problems. From the vantage point of 2013, the case for a technology focused industrial strategy still resonates - but there is no parallel crisis in leadership, despite the constraints of coalition...the new Conservative ... Prime Minister... Alec Douglas-Home ...took charge. Less than a week later, on 23 October, his new Government formally received the Robbins report, entitled Higher Education. A day later, the new administration accepted Lord Robbins's conclusions in full. This was widely expected..." [6] (p. 8).

Willetts adds that: "Because existing universities were not keen to deliver all the extra places [needed as seen by the UGC], there was an unprecedented opportunity to bring some embryonic ideas to life. New universities were established ... [its] origins owe more to an academic debate about modern forms of higher education than to the numbers game." [6] (p. 12) (my emphasis). He also comments, more pertinently for this discussion, about the issues pertaining to women as students. A key point that he makes that: "The report makes two key assumptions about this growth which proved hard to reconcile in practice. First, it assumed a substantial proportion of these extra places would be in science and technology... Secondly, as women were particularly under-represented at university and their forecasts for growth rested on forecasts of better school attainments, this would mean a particularly dramatic surge in the number of female students from $68 \mathrm{k}$ in 1962 to $253 \mathrm{k}$ in 1980). Together these assumptions required a massive shift of girls towards science and technology. This may have been right and desirable but it required a shift in cultural attitudes and patterns of school teaching which could not be delivered in the time available. Robbins correctly forecast a big increase in female students but many more of them went into arts and humanities, which is where overcrowding and resource pressures proved most intense..." [6] (pp. 25-27).

The gloss that Willetts puts upon the issue of student loans seems to be very different from my interpretation: “...to pay for all of this Robbins toyed with the idea of loans repayable as a percentage of future earnings. He decided not to go down this route as he was afraid that positive attitudes to higher education were not sufficiently widespread, especially among young women. Looking back he increasingly came to regret his caution..." [6] (p. 70).

Indeed, he shares the views about women's role in the family that were current at the time of Robbins and which were clearly articulated in the report. For many of us, women and feminists especially, these views are now very old-fashioned and do not accord with the ways we now live our lives. Willetts, however, seems to want a return to what he might think of as halcyon days. But he does mention the changing balances between subjects and faculties in universities, which may have implications for graduate and professional employment. His concerns are about what are now called STEM subjects, namely science, technology, engineering and maths or medicine. And in his case, the focus is firmly on 
medicine and the fact that nowadays even here there is a predominance of women as students, and therefore presumably of doctors.

\section{1963, Robbins and Me}

The Robbins report illustrates the changing times dramatically. 50 years ago most women were not expected to pursue a career throughout their adult lives: marriage and motherhood remained a more important official focus. The Robbins report's reflections on the funding of HE and the way students should be helped through illustrates neatly what a different world it was then. Whilst I did not know the Robbins arguments at the time, their arguments confirm the expectations that many women myself included were brought up with then. And it was the year that I went to university. How things have changed for us all as a society, and in terms of the balances between employment and education in an expanding knowledge economy.

Having mapped out the landscape of HE fifty years ago, and the changing values and views about students and women's role and place, it is clear that the changes have indeed been enormous. In the UK alone we now have more than two million students in HE in the UK, making for a massive increase over the last 50 years. And since the publication of the Robbins report there have been dramatic changes in male and female participation such that females are in the ascendance. Whilst, quite clearly the colleges, schools and universities to which students go vary now in ways they did not at that time. Whilst all of this is welcome news, the question of how it happened and in what ways still needs to be addressed. We still do not know very much from this landscape about who the teachers and academics are in these various different kinds of university and HE. And perhaps more importantly, we still do not know what the future holds, in terms of further transformations in gender equality in the academic labour market, and this is increasingly a time of austerity.

Students were not commonly on the public agenda for discussion and, as women students, we were even rarer. We were a tiny minority of a small minority of young people becoming of age in the 1960s. But students became increasingly vocal as the decade wore on, and this led to the emergence of a strong and campaigning women's liberation movement (WLM), of which I quickly became a part. None of the terms now used about the relations between men and women in $\mathrm{HE}$ and beyond were then in either common currency or in the official lexicon. These are all part of the changing discourse of HE and its political situation - terms like gender equality, feminism and the women's movement. And even less so notions of sexual harassment or abuse, patriarchy and misogyny.

\section{Origins of Second-Wave Feminism 50 Years Ago}

The fiftieth anniversary celebrations for the Robbins report took place alongside several other events in 2013: for example, in the UK as well as the USA about the publication of the American feminist Betty Friedan's book The Feminine Mystique [11] in 1963. This book arguably launched the feminist movement in the USA initially and later in Europe and beyond. The book was based upon Friedan's study of suburban housewives, the majority of whom lived in middle class areas and had been college students, prior to becoming wives and mothers. They all identified what Friedan called "the problem that has no name", namely women's dissatisfaction with their lives as merely wives and mothers, hidden from public and professional lives for which they had studied. This was a major cry for social change 
and the book quickly became a best-seller and launched the National Organisation of Women (NOW) in the USA. Indeed, several of the women that I interviewed mentioned this as most formative in their becoming feminists [5]. For example, Professor Helen Taylor, the feminist literary critic, and Professor Sandra Acker, the feminist sociologist of education both mentioned reading the book as students in the USA and remarking without prompting how influential it was in their journey of thinking about new ways of being a woman and Professor Bronwyn Davies, an Australian feminist sociologist, was also captivated by the book and it transformed her life.

Friedan, along with other feminist writers such as Shulamith Firestone [12,13], Germaine Greer [14], Juliet Mitchell [15,16] Adrienne Rich [17] and Sheila Rowbotham [18-20] were all passionate about changing women's lives: in the family as daughters, sisters, wives and mothers, as sexual beings, and in education, paid and unpaid work or employment. How could women's lives be transformed and made more equal with men's lives in both public and private? How could patriarchy and sexual oppression be overcome? These books led to the enormous development of feminist knowledge and scholarship in global academe, slowly at first but eventually quickening its pace as the twentieth century wore on.

From my study [5], what is particularly significant is how the feminists I interviewed across the three generations were not, as Willetts [7] argued, all middle class but from a variety of family backgrounds. The vast majority of the women — whether middle class or working class — were "first-in-the-family" (a UK concept) or first generation (an American concept) to go to university or college. Of the middle class women, many were the "first-girls-in-the-family", demonstrated the early impact of some form of gender equity, whilst across my three generations of women increasingly the women were both from working class and first in the family to go to university. Importantly too the vast majority of the women are "full" professors in the American sense, and having doctorates, with only tiny numbers of the oldest generation not having them, given the changing requirements of a changing form of HE. This illustrates how expansions of HE, set in train in the UK by the Robbins report, have had an effect on gender equity as a form of social mobility, despite the fact that Conservatives, as represented by Willetts [6] might abhor such developments.

\section{What Is the Complex Jungle of HE Today and Where Is SHE Internationally?}

It is clear from the UNESCO atlas [3] that gender equality is nowhere near being achieved in academe today anywhere in the world but it also signals how gender equality in education is on the global public agenda in ways in which it was not at the beginning of the 21 st century, and certainly not as an international issue during the 20th century. The production of this "evidence" is an important indicator of public policy debates about gender equality, including both the economic and social interests of the global powers. As the Director-General of UNESCO, Irina Bokova, argues in her foreword [5]: "This ... responds to this need on one of the most important questions for human rights and sustainable development today. Girls and women remain deprived of full and equal opportunities for education. (my emphasis) There has been progress towards parity at the primary level, but this tapers off at the secondary level in developing regions. The global economic crisis is deepening inequalities, made worse by cuts in education budgets and stagnating development support."

Gender equality in education has been accepted as a global human right, but how is this interpreted? UNESCO's commitment to gender equality in education has a long history but is it linked to political and feminist campaigning during the 20th century? It is partly but not only and it has now become 
embroiled in neo-liberal policies and politics too. The discourses used about these dramatically increasing numbers are overly optimistic with notions of women being either "favoured" or "beneficiaries". The Atlas argues that Women are the biggest beneficiaries of rising tertiary enrolments. [3] (p. 77) Using a rather odd phrase "globalization has led to more attention to gender egalitarianism" the authors conclude that this is not because of government action - there has rarely been any government policies on affirmative action - but because of social and economic reasons. "Over-representation of women in $\mathrm{HE}$ is not necessarily the result of affirmative action in their favour, for such legislation is rare. Rather, empirical research highlights several reasons for the growing participation of women in post-secondary education, beginning with the fact that higher levels of schooling are now required to attain social mobility and escape poverty..." [3] (p. 84)

They also conclude that whilst there has been an enormous increase in educational participation within and through HE, this has not been matched by greater participation in the labour market. This is then one of the key paradoxes of gender equality in education: is it an indication of continuing forms of sexism, misogyny or patriarchal relations in the wider society? This is what UNESCO says: "Despite the narrowing of the gender gap in tertiary enrolment, significant differences are observed in the fields in which men and women choose to earn degrees ... The proportion of female graduates is much higher in the social sciences, business and law, where women are the majority of graduates in all but one region and in all of the sub-fields of social and behavioural science, journalism and information, business and administration, and law..." [3] (pp. 80-82). The fact remains that men predominate in jobs after the PhD and especially in relation to research posts. The arts and social sciences overall are dominated by women, and also in education "education is the most popular with women" (my emphasis) [3] (p. 82).

The conclusion is that: "It is often the case where a better level of education doesn't necessarily translate into better employment opportunities. Even though women outperform men in education, they still face significant shortfalls and discrimination in the labour market and end up in jobs where they don't use any of their skills. However, even though education is not the only input into women's empowerment it is nonetheless a central one." [3] (p. 107)

It is quite clear that there has been a sea-change in the role of HE in international economies, and that HE is now critical to economic growth throughout the world, known as "academic capitalism" [21] or the knowledge economy. And students are clearly very important to this, including women as students. But what differences does this really make to women's positioning relative to men in the public world of employment and politics, whether in HE or not? Does the fact that there are more women than men students across the globe make any to the relations between men and women in subsequent employment, whether academic or not, and in politics or the public? At a statistical level, as we have already seen from the UNESCO Atlas [3] women have a harder time than men in academic employment, despite getting better grades: that patriarchy still rules in forms of professional employment.

\section{Gender Equality now Part of the Neo-Liberal Project?}

The term gender equality in education is everywhere accepted or acknowledged in political arenas but it has lost its meaning and radical edge. It has been hijacked by government and neutralized. European policies are frequently strongly in favour of gender equality not on social grounds but for economic competition and business innovation, such as a recent gender summit about research in Europe with Mr. Robert-Jan Smits, EC Director General for Research and Innovation [22] arguing that: "The 
promotion of gender equality is part of the European Commission's strategic approach in the field of research and innovation. It contributes to the enhancement of European competitiveness (my emphasis) and the full realisation of European innovation potential." [22] (p. iv)

The European Commission (EC) has produced specific statistics on gender equality in "science", where science is the umbrella term for research across all subjects and disciplines in universities. Their nicely named She Figures - Statistics and Indicators on Gender Equality in Science (EUR 23856 EN) [4] have provided evidence and indicators on gender equality in universities every three years during the 21st century. It is argued that: "The She Figures data collection is undertaken every three years as a joint venture of the Scientific Culture and Gender Issues Unit of the Directorate-General for Research of the European Commission (EC) and the group of Statistical Correspondents of the Helsinki Group".

She Figures 2009 [2] published by the EC paints an interesting picture: in the preface to the report Janez Potočnik, a Slovenian politician who serves as European Commissioner for Science and Research, states that "while there are equivalent numbers of women and men working in the field of Humanities, only $27 \%$ of researchers in Engineering and Technology are female. And what about researchers' career progression? Women account for 59\% of graduates, whereas men account for $82 \%$ of full professors. Do you find that hard to believe? Check out chapter 3." (my emphasis)

He then presents the case for more action by policy-makers [4]: "She Figures 2009 tells us that the proportion of female researchers is actually growing faster than that of men ... The figures are encouraging but the gender imbalance is not self-correcting. She Figures is recommended reading for all policy-makers, researchers, teachers, students, and for parents who share a vision of a democratic, competitive and technologically advanced Europe." (my emphasis)

The report argues for serious action to make gender equality across all science and research more of a reality: "Women's academic career (sic) remains markedly characterised by strong vertical segregation: the proportion of female students (55\%) and graduates (59\%) exceeds that of male students, but men outnumber women among $\mathrm{PhD}$ students and graduates AND academic staff. The proportion of women among full professors is highest in the humanities and the social sciences. The situation thus appears more favourable for the youngest generations of female academics but the gender gap is still persistent (my emphasis)."

\section{Feminist Research on Global HE: Changing the [Patriarchal] Rules of the Game?}

The landscape of HE not only in the UK but across Europe and other nations of the "global north" remains uneven in terms of gender equality, especially for women working as professionals and in HE. There is not only statistical evidence but increasingly feminists are developing critical studies of forms of management and leadership in HE to show how enduring patriarchal patterns are. Is there any evidence to show whether there are any changing gendered patterns of leadership within HE? Barbara Bagilhole and Kate White [23,24], for example, have conducted research studies on this theme. In Gender, Power and Management: A Cross-Cultural Analysis of Higher Education they put together a most exciting and innovative study of women as feminists in global HE. Using feminist perspectives and methods and drawing upon the collaborative network they analyzed gender and power in senior management in universities. What they were specifically interested in were the dynamics of women and men working together in HE management teams and how these dynamics operated cross-culturally. Taking an explicitly "feminist standpoint theory" approach [25] and locating themselves clearly in the 
study, they are able to tease out women's experiences in the different universities they studied. Kate White provides an excellent contextual analysis of legislative frameworks for equal opportunities, including employment and issues around the overarching gender pay gaps, including the impact and influence of specific frameworks on the careers of women within comparative countries. Whilst it is extremely exciting that the Women in HE management (WHEM) network have collaborated to produce this nuanced and carefully executed study, it is also disheartening to find that the picture remains quite bleak for women in senior management. This is largely because there have been contradictory trends both in HE and in the developing economies of which they have become a more critical and central part. So women are now far more in evidence in HE and in senior management but the effects of neoliberalism and managerialism have been to confine women to relatively limited roles, and not the most senior leadership positions.

Similarly, using She figures, Louise Morley [26] (pp. 116-131) argues trenchantly about how what is now called "new managerialism" and the so-called "leaderist turn" in HE, are subverting and reinforcing the "rules of the game" in patriarchal ways. She provides "an international review of feminist knowledge on how gender and power interact with leadership in HE ... to unmask the 'rules of the game' that lurk beneath the surface rationality of academic meritocracy". She argues that: "curiously, in a culture of measurement and audit in HE, women's representation in different roles and grades is not always perceived as sufficiently important to measure, monitor or map comparatively. The Centre for Higher Education and Equity Research (CHEER) at the University of Sussex had to construct its own tables. The data that do exist suggest that women disappear in the higher grades i.e., when power, resources, rewards and influence increase... The highest shares of female rectors (vice-chancellors) were recorded in Sweden, Iceland, Norway, Finland, and Israel. In contrast, in Denmark, Cyprus, Lithuania, Luxembourg and Hungary, no single university was headed by a woman when She Figures reported in 2009 ... This under-representation reflects not only continued inequalities between men and women, but missed opportunities for women to influence and contribute to the universities of the future".

\section{Conclusions}

Morley [27] (p. 29) concludes that "we need new rules for a very different game". It is abundantly clear that gender equality is a highly politicized and contested notion in HE today, given the changes towards neo-liberalism and its impacts upon women's participation in global [and academic] labour markets. Whilst there has been huge transformation in women's participation as students, especially undergraduates, in HE across the globe, this is not matched by significant change in women's participation in academic labour markets as this brief trip through the various statistics for Europe, the UK and the USA amply illustrate. The expansion of universities has gone hand-in-hand with new systems of ranking and changes to academic capitalism [17]. The discourses have changed but the key relations intensified through business and marketing strategies. This intensification is particularly the case in terms of the culture of student and academic life, whereby sexualisation has become increasingly marked. So whilst it is true that there are far more students nowadays and the majority are women this does not mean that there is more than formal equality in terms of "the numbers game". This is controversial as the "numbers game" is a mask for continuing power plays whereby the "rules of the game" remain misogynistic. To develop a more feminist-friendly future, we need to transform the rules of the game. Given the growth of a "laddish culture" in HE [28,29] and the increase in campus sexual assaults in the US which has been 
made public by President Obama [30] in creating a task force to deal with it (22 January 2014), the task of transforming $\mathrm{HE}$ to make women more equal as both students and academics remains a distant prospect.

\section{Conflicts of Interest}

The author declares no conflict of interest.

\section{References}

1. Equality Challenge Unit. Equality in Higher Education: Statistical Report 2011 Part 1: Staff and Part 2: Students; Equality Challenge Unit: London, UK, December 2011. Available online: http://www.ecu.ac.uk (accessed on 9 August 2013).

2. European Commission Directorate-General for Research. She Figures 2009-Statistics and Indicators on gender equality in science, EUR 23856 EN. Available online: http://ec.europa.eu/research/research-eu (accessed on 9 August 2013).

3. UNESCO. World Atlas on Gender Equality in Education. 2012. Available online: http://www.unesco.org/new/typo3temp/pics/d7af2fe604.jpg (accessed on 9 August 2013).

4. Bekhradnia, B. Male and Female Participation and Progression in Higher Education; Higher Education Policy Unit: Oxford, UK, 2009. Available online: http://www.hepi.ac.uk/466-1850 (accessed on 9 August 2013).

5. David, M.E. Feminism, Gender \& Universities, Politics, Passion \& Pedagogies; Ashgate: London, UK, 2014

6. Willetts, D. Robbins Revisited: Bigger and Better Higher Education; Social Market Foundation: London, UK, 2013.

7. Willetts, D. The Pinch: How the Baby Boomers took Their Children's Future-And Why They Should Give It Back, 2nd ed.; Atlantic Books: London, UK, 2011.

8. Michael White. David Willetts leaves Cabinet. The Guardian; 15 July 2014; p. 4.

9. Mooney, C. Diversity in Academe the Gender Issue, Section B; The Chronicle of Higher Education: Washington, DC, USA, 2 November 2012.

10. Report of the Committee on Higher Education. Report of the Committee Appointed by the Prime Minister under the Chairmanship of Lord Robbins 1961-63; Cmnd 2154; HMSO: London, UK, 23 September 1963.

11. Friedan, B. The Feminine Mystique; Penguin: Harmondsworth, UK, 1963.

12. Figes, E. Patriarchal Attitudes: Women in Society; Stein and Day: London, UK, 1970.

13. Firestone, S. The Dialectic of Sex: The Case for Feminist Revolution; Morrow: New York, NY, USA, 1970.

14. Greer, G. The Female Eunuch; Picador: London, UK, 1970.

15. Mitchell, J., Ed. Women: The Longest Revolution: Essays on Feminism, Literature and Psychoanalysis; Virago Press: London, UK, 1984.

16. Mitchell, J. Women's Estate; Penguin: Harmondsworth, UK, 1973.

17. Rich, A. Of Woman Born: Motherhood as Experience and Institution; W.W. Norton: New York, NY, USA; London, UK, 1977.

18. Rowbotham, S. Women, Resistance and Revolution; Penguin: Harmondsworth, UK, 1972. 
19. Rowbotham, S. Hidden from History; Pluto Press: London, UK, 1973.

20. Rowbotham, S. Women's Consciousness: Man's World; Penguin: Harmondsworth, UK, 1973.

21. Slaughter, S.; Rhoades, G. Academic Capitalism and the New Economy Markets, State and Higher Education; The John Hopkins University Press: Baltimore, MD, USA; London, UK, 2004.

22. Smits, R.-J. European Commission (EC) Director General for Research and Innovation; European Commission: Strasbourg, France, 2012.

23. Bagilhole, B., White, K., Eds. Gender, Power and Management: A Cross-Cultural Analysis of Higher Education; Palgrave Macmillan: London, UK, 2011.

24. Bagilhole, B., White, K., Eds. Gender and Generation in Academia; Palgrave Macmillan: Basingstoke, UK, 2013.

25. Harding, S. Feminism and Methodology; Indiana University Press: Bloomington, IN, USA, 1987.

26. Morley, L. The rules of the game: Women and the leaderist turn in higher education. Gend. Educ. 2013, 25, 116-131.

27. Morley, L. Cycles of domination of top roles by men must be broken. Times Higher Education, 6 December 2012; p. 29.

28. Jackson, C. Laddism and the Culture of Higher Education. Seminar Presentation at CHEER; University of Sussex: Brighton, UK, 2014.

29. Phipps, A.; Young, I. Neoliberalisation and "lad cultures" in Higher Education. Sociology 2014, doi: $10.1177 / 0038038514542120$.

30. US President Obama. White House Task Force to Protect Students from Sexual Assault, 22 January 2014. Available online: http://en.wikipedia.org/wiki/White_House_Task_Force_to_ Protect_Students_from_Sexual_Assault (accessed on 9 February 2015).

(C) 2015 by the author; licensee MDPI, Basel, Switzerland. This article is an open access article distributed under the terms and conditions of the Creative Commons Attribution license (http://creativecommons.org/licenses/by/4.0/). 